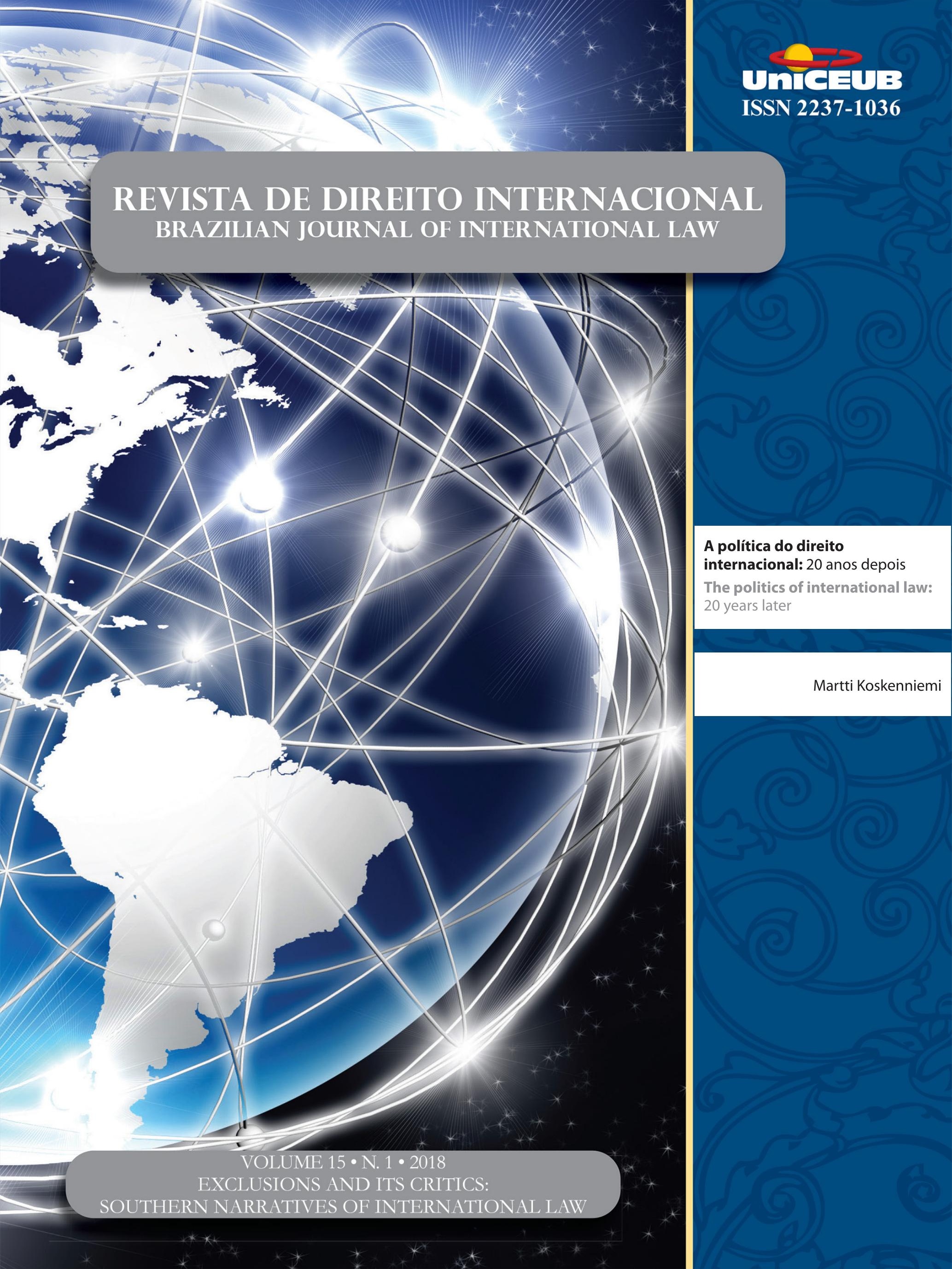




\section{Sumário}

I. Dossiê Especial: Exclusions and its Critics: Southern Narratives of

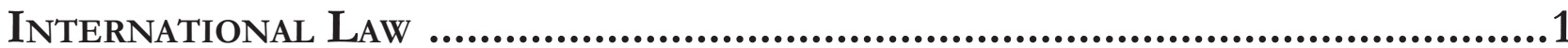

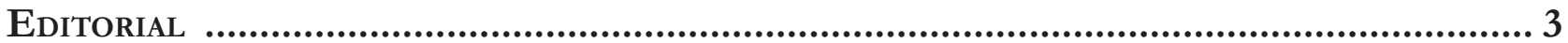

Conseguimos pensar em narrativas críticas do Direito Internacional no Sul Global? ......................... 3

ENTRE A APOLOGIA E A UTOPIA: A POLÍTICA Do DIREITO INTERNACIONAL................................ 6 Martti Koskenniemi e Tradutor João Roriz

A POLÍTICA Do DIREITO INTERNACIONAL: 20 ANOS DEPOIS ...................................................31 Martti Koskenniemi e Tradutor João Roriz

Abordagens terceiro-mundistas para o Direito Internacional: Um Manifesto............42 Bhupinder S. Chimni

Around the pyramid: Political-theoretical challenges to law in the age of global GOVERNANCE

Salem Hikmat Nasser e José Garcez Ghirardi

VOICE AND EXIT: HOW EMERGING POWERS ARE PROMOTING INSTITUTIONAL CHANGES IN THE INTERNATIONAL MONETARY SYSTEM

Camila Villard Duran

LA LIBRE AUTODETERMINACIÓN DE LOS PUEBLOS EN EL SIGLO XXI: UNA APROXIMACIÓN DE LA HISTORIA DEL COLONIALISMO Y EL NEO-COLONIALISMO DESDE LOS PUEBLOS DEL TERCER MUNDO

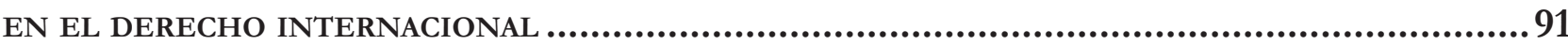

Germán Medardo Sandoval Trigo

INTERNATIONAL CLIMATE CHANGE REGIME AS A PROMOTER OF COLONIAL SYSTEMIC AND SYMBOLIC VIOLENCE: ITS RELATIONSHIP WITH INTERNATIONAL ENVIRONMENT SECURITY AND FOOD SYSTEM THRU THE LENS OF FEMINIST APPROACH 106

Douglas Castro e Bruno Pegorari 
Jus COGENS: AN EUROPEAN CONCEPT? AN EMANCIPATORY CONCEPTUAL REVIEW FROM THE INTER-AMERICAN SYSTEM OF HUMAN RIGHTS

Tatiana de A. F. R. Cardoso Squeff e Marina de Almeida Rosa

O CONHECIMENTO TRADICIONAL RELACIONADO AO COMPLEXO DO CURARE E A LEGISLAÇÃO IN-

TERNACIONAL SOBRE PROPRIEDADE INTELECTUAL. 139

Marcos Vinício Chein Feres e João Vitor de Freitas Moreira

II. Artigos sobre outros temas

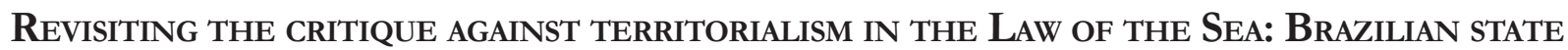
PRACTICE IN LIGHT OF THE CONCEPTS OF CREEPING JURISDICTION AND SPOLIATIVE JURISDICTION ..161 Victor Alencar Mayer Feitosa Ventura

EDUCAÇÃO SUPERIOR INTERCULTURAL, RECONHECIMENTO E REDISTRIBUIÇÃO: O DURO CAMINHO DOS POVOS INDÍGENAS NO EQUADOR 180

Vanessa Wendhausen Cavallazzi, Patrícia Perrone Campos Mello e Raony Soares

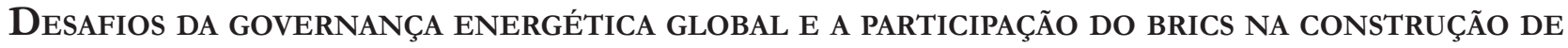
UM NOVO PARADIGMA ENERGÉTICO 200

Fernanda Volpon e Marilda Rosado de Sá Ribeiro

A hermeneutical analysis on the recognition of China as a market economy after 2016.

Alberto Amaral Júnior e Aline Pereira de Carvalho Heringer

THE ISIS ERADICATION OF CHRISTIANS AND YAZIDIS: HUMAN TRAFFICKING, GENOCIDE, AND THE MISSING INTERNATIONAL EFFORTS TO STOP IT

Sarah Myers Raben

The strategic prudence of The Inter-American Court of Human Rights: Rejection OF REQUESTS FOR AN ADVISORY OPINION 255

Cecilia M. Bailliet

Direito Internacional Monocromático: PREVISÃo e apliCaÇÃo dos Direitos LGBTI NA ORDEM INTERNACIONAL 278

Rafael Carrano Lelis e Gabriel Coutinho Galil 
III. RESENHAS

Resenha do livro Empire de Michael Hardt e Antonio Negri 301 Arthur Roberto Capella Giannattasio

Resenha do livro Imperialism, Sovereignty and the Making of International LaW, de

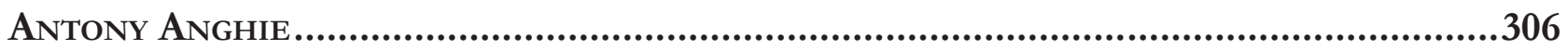

Fabrício José Rodrigues de Lemos e Laura Madrid Sartoretto 


\title{
A política do direito internacional: 20 anos depois*
}

\section{The politics of international law: 20 years later}

\author{
Martti Koskenniemi** \\ Tradutor João Roriz ${ }^{* * *}$
}

\section{Resumo}

Este texto examina algumas das mudanças em meu curso de pensamento sobre a política de engajamento no direito internacional desde a publicação original do artigo que abriu a primeira edição do European Journal of International Law, em 1990. O texto aponta a mudança de foco que vai da indeterminação (com a qual continuo comprometido) dos argumentos legais para os enviesamentos estruturais das instituições internacionais. Em seguida, discute a política de definição, ou seja, a prática estratégica de definir situações e problemas internacionais por meio de novas linguagens especializadas a fim de se obter controle sobre eles. O texto ataca o crescente "gerencialismo" da área e encerra com algumas reflexões sobre a importância do momento histórico do estabelecimento do European Journal, há vinte anos.

\section{Abstract}

The essay examines some of the changes in my own thinking about the politics of engaging in international law since the original publication of the article that opened the first issue of EJIL in 1990. The essay points to the change of focus from indeterminacy (to which I am as committed as ever) of legal arguments to the structural biases of international institutions. It then discusses the politics of definition, that is to say, the strategic practice of defining international situations and problems in new expert languages so as to gain control over them. It attacks the increasing "managerialism" in the field and ends with a few reflections about the significance of the moment of the establishment of the Journal 20 years ago.

* Recebido em 07/11/2017 Aprovado em 28/11/2017

** Professor de Direito Internacional, Universidade de Helsinque.

*** Professor de Direito Internacional, Universidade Federal de Goiás. Email: joao.roriz@ gmail.com

\section{De doutrinas a instituições}

$\mathrm{O}$ artigo que inaugurou o European Journal of International Law, há vinte anos, ressaltou a inevitabilidade da "política" no âmbito do direito internacional público. ${ }^{1}$ Ele o fez analisando em pormenores os problemas doutrinários — soberania, fontes, história, jurisprudência — que são familiares

1 KOSKENNIEMI, Martti. The Politics of International Law. European Journal of International Law, v. 1, n. 1, p. 1-38, 1989. 
a todos os juristas internacionalistas. Foi, obviamente, escrito sob um viés "crítico". Seu estilo e perspectiva seguiram os do realismo legal e dos estudos jurídicos críticos, do estruturalismo convencional e de aspectos da hermenêutica jurídica - embora o texto tenha tentado deixar seus compromissos metodológicos em segundo plano a fim de se dirigir diretamente à área. $\mathrm{O}$ artigo foi inspirado por uma profunda frustração com o isolamento do direito internacional público em relação aos avanços da teoria e metodologia jurídicas, bem como pela convicção de que a ingenuidade da profissão era tudo menos inocente - que ela era, de certa forma, responsável pelo envolvimento do direito internacional público na perpetuação dos próprios problemas que ela oficialmente declarara atenuar. $\mathrm{O}$ artigo não explicitou qual era seu alvo, além da falta de imaginação profissional, e deixou seus próprios compromissos em aberto, isto é, o que pretendia "alcançar" (além de mais complexidade e mais autoconsciência no contexto da profissão). Tampouco explicou o que entendia pela "política" expressa em seu título, a não ser em relação ao tipo de questões que os juristas sempre assinalavam quando discutiam o uso da "discricionariedade" no direito.

$\mathrm{O}$ artigo pode ter sido um pouco ingênuo em supor que a demonstração da natureza contraditória e inconsequente do argumento jurídico — a forma como tudo relacionado ao direito manifestava deferência a pressupostos ("políticos") contestados sobre o mundo - alteraria a visão de mundo desses profissionais; que o artigo forçaria um processo de autoexame que transformaria as preferências das instituições internacionais, levando-as a apoiar causas "progressistas". O tipo de crítica imanente de que era parte realmente não funciona assim. Acima de tudo, é impotente, diante da experiência de que os próprios juristas especialistas podem não levar muito a sério reivindicações de determinação e coerência: "[c]ertamente sabemos que não é tão simples. Claro que há mais elementos por aí.” Nesse caso, a intervenção crítica apenas confirma o que todos já (secretamente) sabiam - e volta-se contra o crítico com a acusação de que este, simplesmente, dormiu no ponto. Além disso, chamar a atenção para a incoerência e o conflito parece implicar que o direito internacional é uma disciplina intelectual que está (ou deveria estar) muito atenta a problemas lógicos. Isso pode ser um equívoco completo. Como ofício, o direito pode, simplesmente, ignorar suas ambições intelectuais como sendo não essenciais.
Lidamos com sérios problemas de paz e guerra, de governança e distribuição. E você está preocupado com coerência. Como se isso fosse, de alguma forma, progressista! E se a coerência e a determinação nunca serão alcançadas de qualquer maneira, por que sua incoerência seria melhor que a nossa?

A demonstração de que "tudo depende da política" não move um centímetro em direção a uma política melhor.

Muitos desses problemas foram discutidos e ressaltados de formas inovadoras ao longo das duas últimas décadas. Uma nova geração de juristas tem avaliado o poder e a fraqueza das críticas, e minhas próprias respostas e revisões foram publicadas em muitos lugares, cujas versões mais completas encontram-se no epílogo da edição de 2005 de From Apology to Utopia e em uma palestra ministrada na London School of Economics em 2007.² Atualmente, há muito mais disposição para refletir sobre os papéis políticos do direito internacional, seus lados sombrios e promissores, do que há vinte anos. Estudantes com ambição intelectual engajam-se, cada vez mais, com temas apresentados, inicialmente, no trabalho de David Kennedy e aprofundados por ele e por muitos outros. As direções desses novos trabalhos são exploradas alhures. ${ }^{3}$ Uma faceta particularmente importante das novas abordagens na área é a forma como lidam com temas pós-coloniais e o fato de serem muitas vezes provenientes de estudantes do Terceiro Mundo, mesmo que estes tenham estudado em universidades do Hemisfério Norte. De qualquer modo, muitas vezes parece que o maior desafio político consiste em saber se uma nova geração de intelectuais terceiro-mundistas é capaz de combinar profissionalismo jurídico com uma nova consciência estratégica dos limites e das possibilidades oferecidas pelo direito internacional para o engajamento político.

2 KOSKENNIEMI, Martti. From Apology to Utopia: the Structure of International Legal Argument. New York: Cambridge University Press, 2005. Para comentários detalhados de leitores, ver sobretudo os textos nos números especiais que marcam a publicação da nova edição do livro (German Law Journal, v. 7, 2006).

3 Ver, por exemplo, CASS, D. Navigating the Newstream. Nordic Journal of International Law, v. 65, p. 341, 1996; RATNER, S.; SLAUGHTER, A-M. (Ed.). The Methods of International Law Washington: ASIL, 2004; ORFORD, Anne. International Law and its Others. Cambridge: Cambridge University Press, 2006; KOSKENNIEMI, Martti. International Legal Theory and Doctrine. Max Planck Encyclopedia of International Law, 2008. Ver também: JOUANNET, E.; RUIZ-FABRI, H.; SOREL, J-M. (Ed.). Regards d'une nouvelle génération sur le droit international. Paris: Pedone, 2008; MARKS, Susan (Ed.). International Law on the Left: Re-examining Marxist Legacies. Cambridge: Cambridge University Press, 2008. 
$\mathrm{O}$ artigo de vinte anos atrás abordou a estrutura da linguagem jurídica internacional. $\mathrm{O}$ acréscimo mais significativo ao texto original é a ênfase no enviesamento estrutural que deixa a análise doutrinária para uma discussão sobre as práticas institucionais, o modo como padrões de preferências fixas são formados e operam em instituições internacionais. Uma demonstração da falta de coerência ("política") do argumento legal é apenas um preâmbulo para uma questão mais importante: a de que, embora todas as justificativas oficiais de tomadas de decisão possam apoiar posições ou resultados contrários, na prática nada é tão aleatório. Juristas competentes sabem que o mundo da prática jurídica é, de fato, bastante previsível. Como Susan Marks argumentou recentemente, a par da demonstração da "falsa necessidade" — hoje um tema crítico clássico —, o que requer demonstração é a "falsa contingência", a ideia de que, uma vez que as estruturas argumentativas estão abertas, tudo é válido. ${ }^{4}$ Os recentes debates sobre governança global e, sobretudo, sobre a fragmentação do direito internacional expuseram, de forma efetiva, o surgimento e funcionamento do enviesamento estrutural. Por meio da especialização — isto é, da criação de regimes especiais de conhecimento e especialização em áreas como "direito comercial", "direito internacional dos direitos humanos", "direito ambiental", "direito e segurança", "direito internacional penal", "direito europeu" e assim por diante -, o mundo da prática jurídica vem sendo fatiado em projetos institucionais que atendem públicos especiais com interesses e princípios também especiais. O motivo da criação de tais instituições especializadas é justamente afetar os resultados produzidos no mundo internacional. Muito pouco é totalmente aleatório por aí, como os juristas praticantes sabem muito bem, ao direcionar seus assuntos para instituições onde esperam encontrar uma receptividade maior.

É por isso que grande parte da busca por direcionamento político hoje assume a forma de conflitos jurisdicionais, de disputas entre vocabulários especializados concorrentes, cada um equipado com um enviesamento específico. Se esses regimes forem ousados em termos de ambição e contarem com o apoio de algum setor poderoso do mundo político, então, podem conseguir mudar o enviesamento geral no direito. Por exemplo, o aumento no número de tratados bilaterais de investimento certamente transformou a relação entre o in-

4 MARKS, Susan. False Contingency. Current Legal Problems, v. 62, p. $1-22,2010$. vestidor privado e o Estado anfitrião em comparação com vinte anos atrás. Em menor escala, o esforço empreendido pelo Tribunal Penal Internacional para a ex-Iugoslávia no caso Tadić, que responsabilizou Estados alheios ao conflito pelo comportamento das partes em uma guerra civil com base no controle geral que exerceram sobre estas, constitui outro exemplo de uma tentativa (talvez malsucedida) de mudar o direito em favor do projeto "contra a impunidade" dos anos 1990. Outros exemplos referem-se à reinterpretação de vocabulários jurídicos gerais como "direitos humanos" em virtude das preferências de novos interesses setoriais - como aqueles relativos à propriedade privada ou à segurança. Uma vez que o termo "direitos humanos", como qualquer outro vocabulário jurídico, é intrinsecamente indeterminado, o que se lê nele (ou fora dele) resume-se a uma sutil estratégia interpretativa. Se um tribunal britânico entender a detenção por tempo indeterminado de uma pessoa no Iraque como uma expressão de direitos humanos, então, essa decisão passará a fazer parte de um padrão mutável de resultados produzidos por instituições que recorrem aos vocabulários de direitos humanos. $^{5}$

Uma atitude mais modesta, mas não necessariamente menos eficaz, é abster-se de ataques ao enviesamento antigo e argumentar "apenas" em termos de uma exceção padronizada. É assim que as novas preferências são geralmente consolidadas. O argumento é o de que, em virtude de "desenvolvimentos recentes" no campo técnico, econômico, político ou de outra natureza (tipicamente ligados a alguma linguagem sociológica sobre "globalização"), surgiram novas necessidades ou interesses que exigem um novo tratamento. $\mathrm{O}$ novo regime - por exemplo, de proteção ambiental ou sobre segurança - procura responder a novos "desafios" não por meio da substituição da norma antiga, mas da simples formulação de uma "exceção" a ela. Às vezes, no entanto, a exceção pode ganhar mais terreno até se tornar a nova regra. Isso, certamente, ocorreu no caso de "di-

5 Com relação ao primeiro exemplo, verificar Case CO/3673 The Queen (on the application of Hilal Abdul-Razzaq Ali Al-Jedda) v Secretary of Defence [2005] EWHC 1809 (Admin), (2007) QB 621 [104]. No mesmo sentido, ver a discussão sobre os argumentos do Procurador-Geral da Austrália a respeito de medidas contraterroristas como implementação de direitos humanos em Carne, "Reconstituting 'Human Security' in a New Security Environment. An Australian, two Canadians and Article 3 of the Universal Declaration on $\mathrm{Hu}-$ man Rights". Australian Year Book of International Law, v. 25, p. 1, 2006. 
reitos humanos" e "comércio". O fato de que muitas faculdades de Direito dos Estados Unidos (e algumas europeias) substituíram cursos de "direito internacional público" por cursos sobre "direito ambiental internacional", "transações comerciais internacionais", "direito internacional penal" ou "direito e globalização" sugere que o centro pode ter desmoronado por completo e que seu lugar tenha sido ocupado por uma pletora de especializações, cada uma com seu próprio idioma preferido, perspectivas de carreira e, é claro, enviesamento estrutural. É por isso que os conflitos políticos mais importantes no âmbito internacional são muitas vezes legalmente articulados como conflitos de jurisdição e de direito aplicável. Tópicos como "comércio e meio ambiente", "segurança e direitos humanos", "desenvolvimento e investimento" dão nome a alguns desses conflitos, enquanto noções como "desenvolvimento sustentável", "responsabilidade de proteger" ou "segurança humana", dentre várias outras, destacam consensos frágeis em áreas em que a luta entre grupos opostos de especialistas e suas preferências (ainda) não foi finalizada. Tais tópicos também revelam temas inovadores no âmbito dos quais juristas ambiciosos gostam de intervir cada vez mais a título de efeito político. Tudo isso se baseia na percepção de que é de grande relevância saber, independentemente do que constitua o direito, qual instituição terá o poder de decisão - por exemplo, se um problema de poluição em uma usina de reprocessamento nuclear é tratado com base no direito universal do regime marítimo ou em um esquema regional de integração econômica; se a gestão dos estoques de pesca é direcionada a funcionários dos setores de alimentos e agricultura (Organização das $\mathrm{Na}$ ções Unidas para Agricultura e Alimentação - FAO), especialistas em comércio (Organização Mundial do Comércio - OMC) ou conservacionistas (Convenção sobre o Comércio Internacional de Espécies da Fauna e da Flora Selvagem Ameaçadas de Extinção - Cites); ou se as atividades de oficiais militares em zonas de conflito devem ser avaliadas pelo prisma dos direitos humanos ou do direito internacional humanitário. ${ }^{6}$

6 O primeiro exemplo é o da usina MOX. Para meus comentários sobre esse tema, ver: KOSKENNIEMI, M. Constitutionalism, Managerialism and the Ethos of Legal Education. European Journal of Legal Studies, v. 1, p. 1-18, 2007. Para o segundo exemplo, ver: YOUNG, M. A. A Legal Framework for Regime Interaction: Lessons from International Trade and Fisheries Regimes. Lauterpacht Centre of International Law, Cambridge, 21 nov. 2008. Para um apelo recente em prol da aplicação dos padrões de direitos humanos (sobrepondo-se ao direito humanitário) em conflitos internacionais, ver: ORAKHELASHVILI, A. The Interaction between Human
Nos dias atuais, a intervenção política é, em muitos casos, uma política de redefinição, ou seja, a definição estratégica de uma situação ou problema ao se recorrer a um idioma técnico, de modo a permitir a aplicação da experiência relacionada a tal idioma, em conjunto com o enviesamento estrutural associado. Nesse caso, apenas a imaginação estabelece o limite. Pensemos em uma ocorrência internacional rotineira, como o transporte marítimo de produtos químicos perigosos. Tal ocorrência pode ser conceitualizada por, pelo menos, meia dúzia de vocabulários acompanhados pelo mesmo número de formas de especialização e tipos de preferência: direito do comércio, direito dos transportes, direito do meio ambiente, direito do mar, "direito químico" e direito internacional dos direitos humanos. Cada uma delas teria algo a dizer sobre o assunto, narrando-o como parte de um conjunto diferente de atividades, valores e prioridades humanas. O direito comercial poderia abordar os acordos comerciais entre os países e suas relações com terceiros. O direito dos transportes poderia destacar as relações jurídico-técnicas entre as diferentes partes em um único contrato de transporte e atribuir jurisdição de forma distinta entre os sistemas jurídicos aos quais elas se submetem. O direito ambiental poderia examinar a natureza da carga e as propriedades do meio ambiente por onde ela passa. O direito do mar poderia tratar da jurisdição do Estado costeiro e do Estado portuário, ou talvez dos padrões relevantes da Organização Marítima Internacional (OMI), enquanto o "direito químico" poderia pautar sua análise na perspectiva das melhores práticas, formas de operação padrão e posição econômica da indústria. Por fim, o direito internacional dos direitos humanos poderia concentrar-se nos perigos para as pessoas envolvidas na viagem, nas condições a bordo do navio e durante o desembarque da carga para as populações locais, e assim por diante. Cada um desses vocabulários provavelmente destacará certas soluções, atores e interesses. Nenhum deles é "mais verdadeiro" que os outros. Cada um atribui visibilidade a algum aspecto enquanto relega outros para segundo plano, preferindo certas maneiras de lidar com o problema em detrimento de outras. O que é considerado significante e o que é empurrado para a escuridão é determinado pela escolha da linguagem por meio da qual se analisa um assunto e que fornece a base para a aplicação de determinado tipo

Rights and Humanitarian Law: Fragmentation, Conflict, Parallelism, or Convergence?. European Journal of International Law, v. 19, p. 161, 2008. 
de direito e de expertise jurídica. O fato de essa escolha não ser geralmente vista como tal — isto é, como uma escolha - pelos vocabulários, mas sim como algo natural, torna-os ideológicos. Se, há vinte anos, parecia intelectualmente necessário e politicamente útil demonstrar a indeterminação (e, portanto, a preferência política) do idioma do direito internacional público, a crítica atual terá que se concentrar no choque entre diferentes idiomas - o direito internacional público como apenas um concorrente entre muitos em relação à autoridade global — e destacar a forma como suas descrições concorrentes operam para impulsionar certos atores ou interesses, relegando outros às sombras.

A política de redefinição diz respeito às mudanças na produção de tipos de resultados nas instituições internacionais, refletindo os esforços dos falantes nativos de algum idioma local em elevar o status desse idioma a uma espécie de esperanto. É disso que se trata a ênfase na "universalidade" em nossa profissão. Pode não ser suficiente simplesmente ocupar o lugar de decisão. Pode-se, também, querer garantir que as decisões pareçam emanar de alguma lógica ou método externos que sejam neutros entre os participantes, que o que entra em ação não é, de fato, o método "de alguém”, mas o método universal (ou "científico") — ou, melhor ainda, não um "método", mas a própria realidade. ${ }^{7}$ Não há nada de novo ou fora de ordem nesse processo - além do fato de que as lutas são descritas pela linguagem neutra do conhecimento especializado. ${ }^{8}$ Isso esconde ou obscurece a natureza contingente das escolhas feitas, o fato de que o que está em jogo é o enviesamento estrutural e não a aplicação de alguma racionalidade neutra, seja ela econômica, ambiental, de direitos humanos ou de segurança. Nessa medida, os vocabulários atuam como "ideologias" no sentido técnico de reificar, de fazer parecer necessário ou neutro algo parcial e contestado. A conscientização do enviesamento, nesse sentido, sugere duas conclusões em relação ao ensino de alunos, à redação de artigos ou à colaboração com colegas. Uma é examinar mais de perto as escolhas estratégicas disponibilizadas por vocabulários específicos de governança global. A outra diz respeito à atitude adequada a se to-

7 Descrevo isso em termos da luta pela hegemonia no Capítulo 9 da seguinte obra: KOSKENNIEMI, Martti. The Politics of International Law. Oxford: Hart Publishing, 2011. p. 219-240.

8 Ver também: KENNEDY, D. The Mystery of Global Governance. Obio Northern University, Petit College of Law, 25 jan. 2008). Disponível em: <www.harvard.edu/faculty/faculty-workshops/kennedy.workshop.pdf>. mar em relação ao gerencialismo subjacente aos atuais debates jurídicos internacionais.

\section{Prática: escolhas estratégicas à vista}

O direito internacional hoje oferece uma grande variedade de instituições e vocabulários especializados com os quais interagimos na prática jurídica. Muitas vezes, como David Kennedy já observou, nos comprometemos com eles sem refletir sobre seus efeitos no mundo dos resultados. ${ }^{9}$ Existe uma crença de que atuar no "direito internacional", nos "direitos humanos" ou no "livre comércio", ou de que trabalhar para instituições comprometidas com "refugiados", "direito humanitário" ou "segurança humana" é, por si só, uma atitude progressista, e que juntar-se aos falantes nativos desses idiomas constitui, automaticamente, um procedimento positivo. No entanto, se a crítica da indeterminação de vinte anos atrás estiver correta, então, tal crença não pode ser automaticamente válida. Pelo contrário, os próprios vocabulários e instituições devem surgir como pontos de controvérsia e acordo no âmbito dos quais "as convenções" predominantes chocam-se, constantemente, contra desafiantes minoritários. Ampla concordância sobre os objetivos institucionais entre juristas de uma mesma área, geralmente, leva a um completo desacordo acerca de como esses objetivos devem ser entendidos e qual seria a melhor forma de abordá-los em dada situação; existem vieses de esquerda e de direita no direito comercial, bem como formas conservadoras e anticonservadoras de falar sobre direitos humanos. A globalização pode ter mudado o locus de engajamento político de "Estados soberanos" para "regimes funcionais". ${ }^{10}$ Contudo, ela, praticamente, não alterou a dinâmica desse engajamento. Trata-se, ainda, de conquistar a posição decisória em uma instituição e, em seguida, de colocar em pauta a agenda de reforma.

É útil pensar no "regime funcional" em analogia com o "Estado soberano" que já existiu um dia. À maneira desse último, os regimes são caracterizados ideologicamente pelo solipsismo e pelo imperialismo, ambos

9 KENNEDY, D. The Dark Sides of Virtue: Reassessing International Humanitarianism. Princeton: Princeton University Press, 2005.

10 Ver: TEUBNER, G.; FISCHER-LESCANO, A. RegimeKollisionen: Zur Fragmentierung des globalen Rechts. Frankfurt: Suhrkamp, 2006. 
sinais de autoabsorção, e pelo desejo de traduzir tudo à volta para seu próprio idioma de preferência. Entretanto, não são "bolas de bilhar", mas estão divididos segundo sua relevância e propósito, e segundo as escolhas estratégicas corretas a serem adotadas em vista de qualquer situação particular, assim como os Estados-nações também o estão. A essa altura, já aprendemos que ter uma identidade nacional específica é algo indeterminado. Ter tal identidade não se vincula a formas particulares de pensar ou de se comportar, ao menos a não ser que se incorpore de forma irrefletida algum fantasma do "espírito nacional" — algo a que os juristas internacionalistas são, por ofício, fortemente contrários. De modo análogo, os vocabulários funcionais são indeterminados, coexistindo com as formas mais variadas de pensar e atuar no mundo. Economistas, ambientalistas e especialistas em direitos humanos estão tão divididos quanto os finlandeses, os franceses ou os fijianos no que tange ao modo como entender o mundo e o que fazer com ele. Os regimes, as instituições e os vocabulários oferecidos aos juristas como linguagens para gerir a "globalização" não têm consequências automáticas: juntar-se a uma instituição ou escolher uma linguagem profissional não equivale mais a encerrar-se em uma gaiola de ferro do que ser um cidadão da Finlândia, da França ou de Fiji. A crítica de vinte anos atrás expôs a indeterminação do direito internacional público. Hoje, a análise crítica terá que fazer o mesmo em relação a esses vocabulários alternativos. ${ }^{11}$ Esta é uma boa notícia na medida em que se consideram as perspectivas de uma vida profissional relevante: há muitas coisas passíveis de redefinição e inovação nos próprios vocabulários. Todavia, para tirar proveito disso, é necessário adotar uma atitude mais matizada diante dos conflitos jurisdicionais e das escolhas associadas sobre efeitos distributivos. Raras vezes é óbvio o lado que se deve tomar nas disputas sobre competência: o idioma comercial pode ser usado para vincular e liberar, assim como o idioma ambiental. Tal opção exige uma sensibilidade crescente para as escolhas estratégicas.

11 Nada é mais fácil do que isso, e muito trabalho tem sido feito, por exemplo, para mostrar a indeterminação dos vocabulários dos direitos humanos, da segurança e do meio ambiente - e assim apontar as escolhas políticas preferidas ou minimizadas por tais tipos de discurso. Até o momento, os enviesamentos do regime comercial têm sido mais presumidos do que rigorosamente demonstrados. Um começo profícuo, não obstante, é ORFORD, A. Trade, Human Rights, and the Economy of Sacrifice. International Law and its Others, p. 166-192, 2006.
Deixe-me dar um exemplo familiar. Ativistas de direitos humanos e especialistas em segurança, frequentemente, escolhem estratégias para "transformar algo em tendência" a fim de aumentar sua influência na política comercial, no governo de Estados falidos ou na cooperação para o desenvolvimento. ${ }^{12}$ Se a estratégia for bem-sucedida, a instituição objeto usará cada vez mais a linguagem dos direitos humanos ou da segurança em seus documentos oficiais, e novas posições administrativas serão abertas para "especialistas em direitos humanos" ou "especialistas em segurança". Embora tudo isso possa, efetivamente, empoderar os ativistas de direitos humanos ou profissionais de segurança, ainda se está muito longe de ter qualquer efeito nos resultados institucionais. Em primeiro lugar, como tentei argumentar anteriormente, qualquer política pode, com algum grau de ingenuidade, ser descrita em termos de "direitos humanos" ou "segurança" graças à amplitude desses termos. Se os resultados institucionais não forem alterados, então, a mudança de vocabulário acabará apenas por espantar a capacidade de transformação originalmente buscada. No entanto, muitas vezes não é claro o que a "preferência por direitos humanos" ou a "preocupação com a segurança" pode implicar. Em projetos de desenvolvimento, por exemplo, é possível recorrer aos direitos humanos para endossar a propriedade privada indígena, mas também para estabelecer cooperativas apoiadas pelo Estado. Podem ser invocados para atacar ou apoiar algum projeto agrícola de larga escala, dependendo se se priorizam as preocupações com a produção de alimentos ou com a prevenção da poluição. Ademais, e os ataques maciços a "postos avançados de terrorismo" suspeitos em países formalmente neutros? Eles realmente limitam ou fomentam o terrorismo? A questão não é que tais perguntas não possam ser respondidas, mas sim que aplicar determinada linguagem pode não acarretar ainda diretrizes claras de ação. É preciso saber de quem o entendimento sobre "direitos humanos" ou qual noção de segurança serão eleitas e, uma vez estabelecida a preferência, que tipo de ação a endossará de forma mais efetiva. ${ }^{13}$

12 Dois estudos sobre tais estratégias aos quais fui recentemente associado incluem: Seppänen, S. Possibilities and Challenges of the Human-Rights Based Approach to Development. Helsinque: The Erik Castrén Institute, 2005 e PAJUSTE, T. Mainstreaming Human Rights in the Context of the European Security and Defence Policy. Helsinque: The Erik Castrén Institute, 2008.

13 Outro estudo recente publicado em Helsinque apresenta alguns desses argumentos: ver NIEMELÄ, P. The Politics of the Responsibility to Protect. Problems and Prospects. Helsinque: The Erik 
É uma experiência corriqueira que, quanto mais ativistas participam do gerenciamento administrativo, mais eles terão dificuldade em identificar as políticas que realmente corroboram os interesses que eles queriam apoiar quando começaram. A abertura de vocabulários profissionais a escolhas discutíveis leva os juristas a análises cada vez mais detalhadas sobre eficiência econômica, adequação administrativa e causalidade social. Todavia, quanto mais urgentes tais questões se tornam, mais o trabalho jurídico passará a ser indistinguível da atividade de outros especialistas, como os especialistas econômicos, os coordenadores administrativos, os sociólogos e assim por diante. Por fim, o que se questiona é se existe (ou se pode existir) qualquer compromisso claro com os "direitos humanos" ou a "segurança" — ou mesmo com o "direito" — que não seria um comprometimento com uma teoria específica de desenvolvimento econômico, equidade na distribuição ou adequação administrativa.

É difícil perceber de que forma os perigos de buscar transformar reformadores institucionais em administradores convencionais poderiam ser evitados sem se estabelecer uma distância crítica completa do "convencionalismo". Há muito a ser dito em favor das vozes críticas que se apresentam à margem dos procedimentos administrativos comuns, a exemplo dos críticos e dos ativistas que defendem os interesses e as preferências daqueles que não são regularmente representados em instituições internacionais. Isso os protege da necessidade de fazer o tipo de escolhas mundanas que cabem aos administradores de forma rotineira e que exigem a redução das preferências de um indivíduo a regras pragmáticas, racionalizadas conforme práticas existentes. No entanto, corre-se o risco de gerar marginalização, irrelevância ou até mesmo a arrogância do martírio, e isso não pode ser recomendado em termos gerais mais que sua contraparte. A escolha de participar ou não é um dilema constante de qualquer política institucional e não pode ser resolvida por uma fórmula geral. Somente podem ser recomendadas a sensibilidade estratégica e a busca pelo distanciamento crítico — qualidades que se opõem à imersão total na cultura administrativa em que se é chamado a trabalhar, ou seja, que se opõem ao gerencialismo.

Castrén Institute, 2008.

\section{TEORIA: CONTRA O GERENCIALISMO}

Desde aquele artigo inicial, muita coisa aconteceu na academia jurídica internacional. Hoje, um corpo crescente de escritos críticos emprega os tipos de técnicas que aquele texto apresentou e incorpora o mesmo tipo de impulso transformador, mas talvez explicitando melhor aquilo que rejeita e o que quer alcançar no mundo. O projeto crítico foi estendido ao direito dos direitos humanos, ao direito internacional penal, ao direito ambiental, à governança pós-conflito, à construção estatal e à "intervenção", entre outros. Novos textos têm buscado estabelecer vínculos com novas linhas de pensamento em direito comparado, direito internacional privado ou direito privado tout court, direito e desenvolvimento, bem como na história jurídica. ${ }^{14}$ Estudos sobre práticas institucionais (em vez de meramente argumentativas) de atores internacionais (Organização das Nações Unidas, organizações intergovernamentais, esquemas e redes especializadas) têm se centrado na lacuna entre promessa e realização. ${ }^{15}$ Tornou-se comum adotar um vocabulário feminista, terceiro-mundista, pós-colonial ou mesmo marxiano e, assim, colocar em primeiro plano os compromissos políticos da análise. ${ }^{16}$ Não é de forma alguma incomum ver textos jurídicos temperados por linguagens antropológicas ou sociológicas, ou por referências e percepções oriundas das relações internacionais, da teoria política ou da economia política.

Mas a "interdisciplinaridade" geralmente é acompanhada de uma política duvidosa. ${ }^{17}$ Penso especificamen-

14 Essa tendência é ampla demais para ser abordada de forma adequada aqui. Para alguns exemplos, ver: Riles, A. (Ed.). Rethinking the Masters of Comparative Law. Oxford \& Portland/Oregon: Hart Publishing, 2001; Knop, K.; Michaels, R.; Riles, A. (Ed.). Transdisciplinary Conflicts of Laws. Law and Contemporary Problems, v. 71, 2008; Trubek, D.; Santos, A. The New Law and Economic Development. Nova York: Cambridge University Press, 2006; Orford (n. 3); Anghie, A. Imperialism, Sovereignty and the Making of International Law. Cambridge: Cambridge University Press, 2004; Berman, N. Passions et ambivalences: Le colonialisme, le nationalisme et le droit international. Paris: Pedone, 2008.

15 Ver, por exemplo: Wilde, R. International Territorial Administration: How Trusteeship and the Civilizing Mission Never Went Away. Oxford: Oxford University Press, 2008; Bhuta, N. Against StateBuilding. Constellations, v. 15, p. 517, 2008.

16 Ver, por exemplo: Chinkin, C.; Charlesworth, H. The Boundaries of International Law: A Feminist Analysis. Manchester: Manchester University Press, 2000; ANGHIE. Imperialism, Sovereignty and the Making of International Law, 2004; MARKS (Ed.). International Law on the Left, 2008.

17 Sem falar da forma como ela serve para fortalecer as fronteiras entre as disciplinas ao dá-las como garantidas e ao perpetuar as 
te no tipo de "gerencialismo" que sugere que os problemas internacionais - problemas da "globalização" - devem ser resolvidos por meio do desenvolvimento de vocabulários técnicos cada vez mais complexos para a formulação de políticas institucionais. Encontra-se isso muitas vezes na recomendação de substituir os costumes arcaicos do direito internacional por uma linguagem inspirada na ciência política de "governança", "regulação" ou "legitimidade". A abordagem gerencial é crítica em relação aos aspectos formais do ofício jurídico, que considera muitas vezes como um obstáculo para a ação efetiva. Sua preferência reside nos "regimes" informais e seu foco centra-se na (no fato da) "conformidade", não na análise (normativa) daquilo a que se deve conformar. O gerencialismo pretende efetivar os "interesses" mais ou menos não problemáticos dos "atores" (geralmente identificados como Estados de bola de bilhar). Para tal, os objetivos da ação institucional são dados e as únicas questões remanescentes dizem respeito ao seu modo otimizado de realização. A posição fantasia do gerencialista é a de segurar a orelha do príncipe - daí a ânsia por resultados concretos, isto é, a insistência em uma proposta política no final do artigo. ${ }^{18}$ Para o gerencialista, questões normativas sobre os fins de uma ação ou sobre a ordem certa entre fins conflitantes surgem, apenas, na linguagem da "legitimidade", que as traduz em "sentimentos" empiricamente manobráveis no seio de determinado público. ${ }^{19} \mathrm{Uma}$ vez que o comportamento não é causado pelo direito, mas sim pela "coincidência entre interesse e coerção", o gerencialista só consegue enxergar a "interdisciplinaridade" como um caminho para a aquisição acadêmica: "existe uma literatura de direito internacional mais sofisticada no subcampo de relações internacionais da ciência política". ${ }^{20}$

Contudo, quanto mais se concebe o direito internacional nesses termos, mais tolo se parece. As causalida-

identificações disciplinares dos participantes apresentando-os como "representantes" de determinadas orientações acadêmicas.

18 Discuti essa questão em: KOSKENNIEMI, Martti. Constitutionalism as Mindset: Reflections on Kantian Themes about International Law and Globalization. Theoretical Inquiries in Law, v. 8, n. 1, p. 9, 2007. Ver também o Capítulo 13 da seguinte obra: KOSKENNIEMI, Martti. The Politics of International Law. Oxford: Hart Publishing, 2011. p. 307-330.

19 Ver também: KOSKENNIEMI, Martti. Legitimacy, Rights and Ideology: Notes towards a Critique of the New Moral Internationalism. Associations. Journal of Legal and Social Theory, v. 7, p. 349, 2003.

20 Goldsmith, J.; Posner, E. The Limits of International Law. Oxford: Oxford University Press, 2005. p. 15. des do mundo são por demais complexas, e as simplificações estratégicas, por demais grosseiras. O "interesse" funcional não é um pressuposto político sólido para se “aplicar", mas um objeto de controvérsia interpretativa, instável no lugar e no tempo e tão indeterminado como a "regra" que deveria substituir — embora, obviamente, acompanhado por um enviesamento diferente, o da elite da ciência política. Não se trata apenas de um problema sobre o anacronismo de um sugerido retorno no tempo (de inocência?) anterior ao Positivismusstreit das décadas de 1960 e 1970, ou seja, antes do colapso da ideia de que a ciência social normativa deveria ser construída por meio do idioleto da explicação e da previsão comportamental. ${ }^{21}$ Obviamente, os conhecimentos empírico e técnico têm seus usos. Eles aguçam a análise e oferecem uma visão mais clara das alternativas de ação disponíveis. Entretanto, não têm nada a dizer que seja de interesse normativo e muito menos emancipatório. ${ }^{22}$ Ainda assim, o gerencialismo tem uma normatividade oculta que privilegia valores e atores que ocupam posições dominantes em instituições internacionais, os quais, portanto, não têm razão para assumir uma atitude crítica em relação a estas. O gerencialismo reforça a ideia de que questões de distribuição e preferência já foram decididas alhures, e tudo o que resta são questões técnicas, questões de como suavizar o caminho do príncipe.

Por outro lado, quanto mais penso na tradicional Teoria (europeia) da Exegese e no gerencialismo que procura desafiá-la, mais os dois parecem habitar o mesmo espaço conceitual. A busca pela interpretação correta de um conceito e a derivação ótima de uma política a partir de alguma noção de "interesse" parecem igualmente atraídas pela busca por uma resposta correta e pela crença de que é possível ter acesso a ela por meio de um raciocínio técnico - no primeiro caso, por meio de interpretação, e, no segundo, de uma "escolha racional". Ambos são igualmente insistentes em minimizar o papel da vontade e da aleatoriedade, da paixão e da ideologia na forma como o mundo é governado, bem como suas próprias implicações sobre ele. Embora ambos recaiam modestamente no contextualismo de cada solução oferecida, cada um ainda considera a si mesmo como uma teoria ou método geral. Com isso, atribuem

21 Para uma introdução, ver: Adorno, T. (Ed.). The Positivist Dispute in German Sociology. Londres: Verso, 1976.

22 Para outra introdução, ver: Habermas, J. Knowledge and Human Interest. Cambridge, MA: MIT Press, 1976. 
poderes de decisão aos falantes nativos de seus vocabulários auxiliares e, portanto, conseguem mudanças sutis no padrão de decisões e resultados institucionais. $\mathrm{Na}$ melhor das hipóteses, ambos revelam alguma experiência participante do mundo e, assim, nos permitem planejar e nos comunicar de modo profissional nas instituições internacionais. Na pior das hipóteses, obscurecem o modo como o poder funciona e fazem hierarquias intelectuais ou sociais específicas parecerem aspectos naturais de nossas vidas.

Isso sugere que a justaposição entre o formalismo constitucional europeu e o desafio "imperial" às instituições internacionais perpetrado pelos Estados Unidos nos últimos anos - tema de muita preocupação no meio acadêmico - é, de certo modo, equivocada. Entender que o compromisso com o "direito" constitui uma escolha automaticamente progressiva é uma diretiva política tão grosseira quanto a crença de que tudo precisa ser simplificado rumo à obtenção de preferências imperiais. A pergunta sempre permanece: que tipo de direito (ou de quem) e que tipo de preferência (e de quem)? O constitucionalismo e o império vão bem juntos, como testemunharam tanto a experiência europeia do século XIX quanto a estadunidense de hoje. Obviamente, o constitucionalismo proposto sobretudo pelas universidades alemãs nos dias atuais está culturalmente vinculado à (ou tem um enviesamento para) transparência e responsabilização, aspectos valiosos das vidas institucionais. ${ }^{23}$ Todavia, estas não são provas de que constituem uma fachada para a estase, e é sempre necessário perguntar o que está incluído na constituição e o que é deixado de fora (como "privado", por exemplo, ou "científico") e quem a constituição atual alça a cargos de tomada de decisão. Aprovo totalmente o movimento político que visa redefinir o mundo gerencial das instituições internacionais por meio de vocabulários constitucionais ou administrativos — não em virtude do valor intrínseco desses vocabulários, contudo, mas do desafio crítico que representam para a atual cultura de um domínio especialista apolítico, e talvez do apelo da perfectibilidade (kantiana) que criaram como um objetivo regulador para as instituições humanas. ${ }^{24}$ No

23 Para a política do constitucionalismo, consultar: por Bogdandy, A. von et al. The Exercise of Public Authority by International Institutions. German Law Journal, v. 9, p. 1375, 2008. Para o foco nos vocabulários administrativos, ver: Kingsbury, B.; Krisch, N.; Stewart, R. B. (Ed.). The Emergence of Global Administrative Law. Law \& Contemporary Problems, v. 68, 2005.

24 Ver: KOSKENNIEMI, Martti. Constitutionalism as Mindset. entanto, o direito não é uma panaceia. Problemas na "guerra contra o terror", por exemplo, não emergem da ausência do "direito" ou de "direitos" — na verdade, uma grande quantidade de leis e regulações permite e direciona as atividades dos indivíduos envolvidos. ${ }^{25}$ Isso significa que, simplesmente, tornar algo "legal" ou uma questão de "direitos" não será suficiente para assegurar o beneficiamento de determinada escolha. Será que uma autorização do Conselho de Segurança para a Guerra do Iraque teria de fato mudado nosso entendimento sobre o conflito? Deveria tê-lo feito? Mais uma vez não se pode evitar o recurso a escolhas estratégicas. Ou, de forma mais realista, não se pode evitar oscilar entre descobrir a escolha estratégica correta e recuar a formas institucionalmente convencionais de atuar como verdadeiras regras relativas a políticas adequadas.

Um antídoto para a exegese e o gerencialismo consiste em focar a história, tendência tão marcante no contexto recente do direito internacional. Tal foco pode ter sido inspirado em uma preocupação puramente historiográfica: a noção de que pouco tem sido feito para elucidar o papel frequentemente ambivalente que o direito e os juristas desempenham na formulação de políticas e nos conflitos, ou de que as histórias convencionais pecaram por excesso no que tange à hagiografia ou espremeram as causalidades do mundo em narrativas históricas excessivamente homogêneas. As novas histórias têm tentado estabelecer um entendimento corrente de que a profissão não consiste somente em limitar o uso do poder, mas em permitir e facilitar o uso do poder. Elas têm sido muitas vezes motivadas por uma preocupação normativa, sobretudo pela intuição de que algum aspecto da política de hoje é mais bem entendido como uma versão ultrapassada de algum antigo padrão de privilégio (tipicamente o eurocentrismo, o colonialismo ou a "missão civilizatória"). ${ }^{26}$ A historia magistra vitae pode

Reflections on Kantian Themes about International Law and Globalization. Theoretical Inquiries in Law, v. 8, n. 1, p. 9-36, 2007 (acima da nota 18, p. 33-36).

25 Ver: Kennedy, D. Of War and Law. Princeton: Princeton University Press, 2006; JOHNS. Guantanamo Bay and the Annihilation of the Exception. European Journal of International Law, v. 16, p. 613, 2005.

26 Ver especialmente os trabalhos de: BERMAN. Passions et ambivalences: Le colonialisme, le nationalisme et le droit international (2008) e Anghie. Imperialism, Sovereignty and the Making of International Law (2004), e, por exemplo, o trabalho fortemente histórico de Mieville, C. Between Equal Rights: A Marxist Theory of International Law. Leiden: Brill, 2005 e o de Jouannet, E.; Ruiz-Fabri, H. Imperialisme et droit international en Europe et aux Etats-Unis. Paris: Société de Législation compareé, 2007. 
ser uma base metodologicamente duvidosa sobre a qual argumentar em prol da importância da história. Como um estilo de escrita legal, porém, a narrativa histórica liberta a imaginação política para se mover mais livremente no mundo das escolhas alternativas, lançando luz tanto sobre suas necessidades falsas quanto sobre suas contingências falsas.

\section{O European Journal of International LAW}

Há alguns anos, publiquei um relato sobre o estabelecimento do primeiro periódico de direito internacional, a Revue de droit international et la legislation comparée, em 1869 , e sobre a primeira sociedade profissional internacional, o Institut de droit international, em 1873, como parte do entrincheiramento liberal europeu depois de um período de progresso no continente, à medida que as nuvens da futura crise começavam a aparecer no horizonte político. ${ }^{27} \mathrm{O}$ direito internacional nasceu de um movimento voltado para a defesa de um projeto liberal-internacionalista em um momento de perigo e de oportunidade. Os homens de 1873 sabiam o que Lênin sabia, ou seja, que um periódico é não apenas um propagador ou um agitador coletivo, mas também um organizador coletivo. Suponho que também houve muito dessa mentalidade na criação do European Journal of International Law em 1989 e da European Society of International Law alguns anos depois. Há vinte anos, tal qual ao final do século XIX, os juristas, animados com aquilo que os "homens de 1873" chamavam de seu esprit d'internationalité, reagiram às mudanças em curso no mundo, voltando-se para um profissionalismo intensificado com um ethos modernizador. ${ }^{28}$ Tal reação seria organizada com base em uma variedade de locais distintivos. Em 1873, os locais-chave eram a Universidade de Columbia, Ghent, Heidelberg e Genebra; em 1989, Florença, Munique, mais uma vez Genebra, e Greenwich Village. O objetivo era transformar uma posição de privilégio em causas progressivas (e, inevitavelmente, vice-versa). O European Journal tornou-se, desde então,

27 Koskenniemi, M. The Gentle Civilizer of Nation: The Rise and Fall of International Law 1870-1960. Cambridge: Cambridge University Press, 2001. p. 11-97.

28 De fato, durante e após 1989, a mudança internacional pareceu muitas vezes retrógrada, em direção a um futuro que deveria ter sido naquela época. uma das publicações mais interessantes da área, e a Universidade de Nova York passou a ser considerada o lar da escola de direito europeu mais prestigiada do mundo. Contudo, é mais difícil dizer se isso se traduziu em influência política ou que rumo tomou tal influência. $\mathrm{O}$ fato de o periódico ter deixado de aceitar manuscritos em francês diz muito sobre a "Europa" constante do seu título. No entanto, projetos políticos significativos não estão, necessariamente, ligados a determinada base territorial, a um Nomos. Os argumentos anteriormente mencionados sugerem que rotular um projeto sob o título "Europa" pode evocar todo tipo de associações culturais e políticas ambivalentes. Trata-se de uma escolha estratégica que não pode reduzir-se ao alinhamento com um ethos utópico inerente em um nome tão sobrecarregado. Ainda assim, deve-se ter em mente que o que essa escolha empreende no mundo não pode ser continuamente repensado em termos estratégicos. Como qualquer nome ou conceito, ela recebe independência; ela passa a ser portadora autônoma de um enviesamento, e a adotamos como uma segunda natureza, um lar e uma fé, uma prisão e uma porta aberta. 
Para publicar na Revista de Direito Internacional, acesse o endereço eletrônico www.rdi.uniceub.br ou www.brazilianjournal.org.

Observe as normas de publicação, para facilitar e agilizar o trabalho de edição. 